\title{
Baby Check and the Avon infant mortality study
}

\author{
T J Cole, R E Gilbert, P J Fleming, C J Morley, P T Rudd, P J Berry
}

\begin{abstract}
Thirty seven sudden, unexpected infant deaths from the Avon study were scored retrospectively for serious illness using a modified version of Baby Check. Three cases $(8 \%)$ scored very highly. In a small proportion of sudden deaths, Baby Check could have identified serious illness before death and led to hospital admission.
\end{abstract}

Baby Check is a scoring system to help parents and doctors quantify serious illness in babies up to 6 months of age. ${ }^{1}$ It is based on seven symptoms and 12 signs, each of which has a particular score. The individual scores are added together to give an overall score, and the higher it is the more ill the baby. Scores below 8 indicate 'the baby is well or only mildly ill and is not likely to need medical attention at the moment'. Between 8 and 12 'the baby is unwell but not likely to be seriously ill-contact your doctor, health visitor or midwife for advice'. Between 13 and 19 'the baby is ill and needs to be seen by a doctor'. If the score is $20+$ 'the baby may be seriously ill and needs to be seen by a doctor straight away'.

A proportion of babies dying suddenly and unexpectedly may be seriously ill before they die, but with unrecognised symptoms. ${ }^{2}$ To investigate this, the mothers of Avon infants who died suddenly and unexpectedly during a period of nine months, and two age matched controls, were asked about their baby's symptoms and signs in the $\mathbf{2 4}$ hours before the baby's death or interview respectively.

\section{Nutrition Unit, Cambridge}

MRC Dunn

T J Cole

Bath Unit for Research into Paediatrics

R E Gilbert

$P$ T Rudd

Institute of Child Health,

University of Bristol

P J Fleming

Department of

Paediatrics,

University of Cambridge

C J Morley

Department of

Paediatric Pathology, Bristol Maternity

Hospital

P J Berry

Correspondence to: DrC J Morley, Department of Paediatrics, Level 8,

Addenbrookes Hospital

Hills Road

Cambridge CB2 2QQ

Accepted 2 June 1991

(ArchDisChild 1991;66:1077-8)

\section{Methods}

The mothers of 38 infants who died suddenly and unexpectedly and 76 matched controls ${ }^{3}$ were interviewed. Using questions based on Baby Check, all but four items were scored retrospectively: rectal temperature, big toe squeeze, hernia, and crying during assessment. One 12 month old infant who died and his two controls were excluded from the analysis.

\section{Results}

Table 1 gives the distribution of Baby Check scores by illness grade for the sudden deaths and for the controls. Eleven per cent of babies in each group scored $8+$, but only one control $(1 \%$, score 20$)$ as against three of the infants who died $(8 \%$, scores 26,33 , and 44$)$ scored $20+$. All the infants who died were clearly ill, while the controls were apparently well (table 2).
Table 1 Distribution of Baby Check scores in 37 infants dying suddenly and unexpectedly and 74 age matched controls

\begin{tabular}{lclc}
\hline Illness grade & $\begin{array}{l}\text { Score } \\
\text { range }\end{array}$ & $\begin{array}{l}\text { No (\%) } \\
\text { cases }\end{array}$ & $\begin{array}{l}\text { No (\%) } \\
\text { controls }\end{array}$ \\
\hline $\begin{array}{l}\text { Well/mildly ill } \\
\text { Needs advice }\end{array}$ & $0-7$ & $33(89)$ & $66(89)$ \\
$\begin{array}{l}\text { Needs to be seen } \\
\begin{array}{l}\text { Needs to be seen urgently } \\
\text { and probably admitted }\end{array}\end{array}$ & $13-12$ & $-19(3)$ & $3(4)$ \\
\hline
\end{tabular}

Table 2 Babies with Baby Check scores of $13+$

\begin{tabular}{|c|c|c|c|}
\hline Score & $I D$ & Group & Findings ("indicates 'explained' death) \\
\hline 44 & 80 & Case & $\begin{array}{l}\text { *Intracranial haemorrhage and } \\
\text { gastrointestinal bleeding (two day } \\
\text { history) }\end{array}$ \\
\hline 33 & 79 & Case & $\begin{array}{l}\text { *Staphylococcus aureus septicaemia } \\
\text { and pyelonephritis (16 hour } \\
\text { history) }\end{array}$ \\
\hline 26 & 94 & Case & $\begin{array}{l}\text { Adenovirus type } 5 \text { isolated from } \\
\text { nasopharynx }\end{array}$ \\
\hline 20 & 95B & Control & $\begin{array}{l}\text { Nothing significant, no medication, } \\
\text { saw doctor two weeks earlier }\end{array}$ \\
\hline $\begin{array}{l}16 \\
15\end{array}$ & $\begin{array}{l}95 \mathrm{~A} \\
80 \mathrm{~A}\end{array}$ & $\begin{array}{l}\text { Control } \\
\text { Control }\end{array}$ & $\begin{array}{l}\text { Nothing significant } \\
\text { Reported as having laryngeal stridor } \\
\text { from soon after birth }\end{array}$ \\
\hline 14 & 72 & Case & $\begin{array}{l}\text { Respiratory syncytial virus isolated } \\
\text { from nasopharynx and trachea }\end{array}$ \\
\hline 13 & 82B & Control & Nothing significant \\
\hline
\end{tabular}

\section{Discussion}

A minority of infants dying suddenly and unexpectedly had signs and symptoms consistent with serious illness. Eight per cent of the infants who died appeared to be seriously ill, appreciably less than the $24 \%$ found in Knowelden's report, ${ }^{2}$ with at least five separate symptoms/signs and Baby Check scores of $26+$. In field trials of babies brought to hospital, ${ }^{4}$ scores of $20+$ had a $67 \%$ predictive value for needing hospital treatment. Scores of 33 or 44 were rare even in paediatric outpatients, with a $100 \%$ predictive value for hospital treatment. Had these high scoring babies been taken to hospital they would probably have been admitted, and might not have died.

Two victims (79 and 80, table 2) were 'explained' deaths, with clear cut pathology. The other two 'explained' deaths were a baby with a perforated stomach, who was asymptomatic when put to bed, and a baby with heart failure due to an atrioventricular canal defect, who was always mildly cyanosed and breathless. Both babies scored low. The third high scoring case (94, table 2) was not an 'explained' death, but adenovirus was isolated at postmortem examination.

Fewer control babies scored 0-7 (89\%) than in the Baby Check field trials of mothers at 
home (97\%). ${ }^{5}$ Here the mothers did not see the explanations in the Baby Check booklet, so they probably used less stringent criteria for each symptom/sign, and overscored. All three controls scoring 13-19 (table 2) had either green vomit (13 points) or recession (15 points), which are very rarely seen in the community. These would probably have been reported absent with Baby Check, where parents are told not to score items if in doubt.

The results suggest that Baby Check could help parents recognise a small proportion of babies at risk of sudden unexpected death. Babies who die suddenly and unexpectedly are more likely to be taken to the general practitioner in the week before death than control babies. ${ }^{6}$ This difference is unrelated to reported symptoms, but parents clearly react to their perception of the babies' well being. If such families used Baby Check they might be empowered to obtain timely medical help, so that some of the babies would not die.

1 Morley CJ, Thornton AJ, Cole TJ, Hewson PH, Fowler MA Baby Check: a scoring system to grade the severity of acute systemic illness in babies under 6 months old. Arch Dis Child 1991;66:100-5.

2 Knowelden J, Keeling J, Nicholl JP. A multicentre study of postneonatal mortality. London: HMSO, 1984.

3 Fleming PJ, Gilbert R, Azaz Y, et al. Interaction between bedding and sleeping position in the sudden infant death syndrome: a population based case-control study. $B M \mathcal{F}$ 1990;301:85-9.

4 Thornton AJ, Morley CJ, Cole TJ, Green SJ, Walker KA. Field trials of the Baby Check score card in hospital. Arch Field trials of the Baby Child 1991;66:115-20.

5 Thornton AJ, Morley CJ, Green SJ, Cole TJ, Walker KA, Bonnet JM. Field trials of the Baby Check score card: mothers scoring their babies at home. Arch Dis Child 1991; 66:106-10

6 Gilbert RE, Fleming PJ, Azaz Y, Rudd PT. Signs of illness preceding sudden unexpected infant death. BMF 1990;300: 1237-9.

\title{
Guillain-Barré syndrome in three siblings less than 2 years old
}

\author{
Gad Bar-Joseph, Amos Etzioni, Jeshaiahu Hemli, Ruth Gershoni-Baruch
}

\begin{abstract}
Three of five children who were born to consanguineous parents developed GuillainBarré syndrome before they were 3 years old. The syndrome is rare in early childhood and we suggest that there may be a genetic element in the pathogenesis.
\end{abstract}

Polyradiculoneuritis (Guillain-Barré syndrome) has become the most common form of acute paralysis since the decrease in the incidence of poliomyelitis. ${ }^{1}$ Though the incidence in children seems to be increasing, it is still rare below the age of 2 years. ${ }^{2-3}$ There have been only three reports of familial Guillain-Barré syndrome in adults, and none in children, to our knowledge. ${ }^{4-6}$

We describe three siblings from a consan-

Rambam Medical Center and Technion Faculty of Medicine, Haifa,

Israel

Pediatric Intensive

Care Unit

Gad Bar-Joseph

Department of

Pediatrics A

Amos Etzioni

Ruth Gershoni-Baruch

Department of

Neurology

Jeshaiahu Hemli

Correspondence to:

DrBar-Joseph.

Accepted 2 April 1991

(ArchDisChild 1991;66:1078-9)

\section{Case reports}

CASE 1

A 2 year old boy was admitted to another hospital in 1980 with progressive weakness and difficulty in swallowing. Two weeks before admission he had a short febrile illness and a cold. On admission he was pale and in a 'poor general condition', with drooling, generalised hypotonia and hyporeflexia. Results of laboratory tests did not indicate a diagnosis.

The child was treated with corticosteroids and intravenous fluids replacement. His condition deteriorated and he died on the sixth day in hospital with the presumptive diagnosis of encephalitis.

\section{CASE 2}

The younger sister of case 1 was admitted to this hospital in 1984 at the age of 22 months because of weakness in the lower limbs. One week before admission she had had pharyngitis, and subsequently she became sleepy and developed unstable gait. Neurological abnormalities included ataxic gait, inability to stand, and areflexia. Examination of the cerebrospinal fluid showed no cells, glucose $3 \cdot 1 \mathrm{mmol} / \mathrm{l}$, and a protein concentration of $1.6 \mathrm{~g} / \mathrm{l}$. The electroencephalogram was interpreted as normal. Electromyography showed reduced nerve conduction velocity with prolongation of distal motor latency. Poliomyelitis was ruled out. HLA typing failed to show the DR3, A3, and B8 antigens.

Within a week she started to improve spontaneously, and at follow up examination two years later she had no neurological deficit.

\section{CASE}

The younger brother of case 2 was admitted to the paediatric intensive care unit in 1987 at the age of 9 months with respiratory failure follow- 